\title{
Incidence, risk factors, clinical profile, and determinants (affecting outcome) of new onset acute kidney injury developing in critically Ill patients in pediatric intensive care unit of a tertiary hospital in middle India
}

\author{
Rao B.N. ${ }^{1}$, Rathia S.K. ${ }^{2}$, Phuljhele S. ${ }^{3}$, Verma Y.K. ${ }^{4}$, Amle D. ${ }^{5}$ \\ ${ }^{1}$ Dr. Badri Narayan Rao, Associate Professor, ${ }^{2}$ Dr. Santosh Kumar Rathia, Assistant Professor, ${ }^{3}$ Dr. Sharja Phuljhele, \\ Professor \& HOD, ${ }^{4}$ Dr. Yogendra Kumar Verma, PG Student; above all authors are affiliated to Pt. J.N.M. Medical \\ College, Raipur, Chhattisgarh from the Department of Pediatrics, ${ }^{5}$ Dr. Dnyanesh Amle, previously Assistant Professor in \\ Biochemistry at the same institute, now at AIIMS, Nagpur, India.
}

Corresponding Author: Dr. Santosh Kumar Rathia, MIG (Deluxe)-217, Phase-2, Kabirnagar, Raipur, Chhattisgarh, India. E-mail: drsantoshrathia84@gmail.com

\begin{abstract}
Aim/Objectives: To study the incidence, clinical-profile of AKI developing in critically-ill children after admission to PICU, including its risk-factors and determinants affecting patient outcome. Material/Methods: This prospective observational study was conducted at a tertiary teaching hospital (Pt JNM Medical College Raipur, CG, India) over a study period of 12 months (August 2017-July 2018). Those patients who satisfied the inclusion-criteria of having criticalillness requiring PICU admission, age between 1month to 18 years, and developing in-hospital AKI were enrolled; and after obtaining written informed-consent from parents, their basic demographic, clinical details and laboratory reports were entered from case records into predesigned proforma and then data was compiled in Microsoft Excel-Sheet. AKI staging was obtained using pRIFLE criteria (2007) and compared with renal-recovery and patient-survival. SPSS software (version 21) was used for data-analysis and p-value $<0.05$ was taken for statistical significance. Results: Out of total 1042 critically-ill children admitted during study-period, 103 developed new-onset AKI in PICU (overall incidence 9.8\%). Among them, 96 patients died (93.2\% cases). Maximum subjects developing in-hospital AKI had three major associated fatal risk-factors like refractory shock (80.5\%), severe sepsis (68\%) and MODS (62.1\%). But only MODS $(\mathrm{p}=0.002)$ and refractory-shock $(\mathrm{p}=0.0001)$ showed significant association with fatal outcome. Maximum new-onset AKI cases developed within 3 days of PICU admission (62\%). No statistically-significant association was observed between different AKI-stages and renal-recovery or patient-survival. Conclusion: Sepsis was common underlying risk-factor for new-onset AKI in critically-ill patients admitted in PICU, while association of MODS and/or refractory shock majorly determined poor survival-outcome.
\end{abstract}

Keywords: New-onset AKI, Incidence, Risk-factors, p-RIFLE, Outcome, Determinants

\section{Introduction}

Acute kidney injury (AKI) or acute renal failure (ARF), is usually defined as an abrupt decline in renal function, presenting clinically as a reversible acute increase in nitrogenous wastes (blood urea nitrogen and serum creatinine levels) over the course of few hours to weeks. There is trend of significantly higher incidence of AKI amongst critically ill patients of ICUs compared to all patients admitted to any hospital. Recent two studies have reported overall incidence of new-onset AKI in

Manuscript received: $10^{\text {th }}$ May 2019

Reviewed: $20^{\text {th }}$ May 2019

Author Corrected: $27^{\text {th }}$ May 2019

Accepted for Publication: $31^{\text {st }}$ May 2019 critically sick PICU subjects to be $36 \%$ \& $25 \%$, while it was only $9 \%$ \& $5.2 \%$ respectively in non critical pediatric admissions $[1,2]$. In the critically ill patients (both in adults and children), sepsis is the major cause or risk-factor for AKI, accounting for nearly $50 \%$ of cases. Sepsis, shock and/or MODS are major determinants of poor outcome as well, as shown by various observational studies [1,3]. Mortality rates in critically ill paediatric patients developing AKI are usually high, ranging between $9 \%$ and $67 \%$. [4,5]. Acute renal insult' is currently defined/categorized based on severity of renal compromise based on RIFLE 
[6] or more specifically 'pRIFLE criteria'[7] for pediatric patients. Such severity staging of AKI also determines the chance of renal-recovery as well as patient survival outcome.

This study had been planned to assess the actual burden of new-onset AKI amongst critically-sick pediatric patients in a tertiary care PICU in middle India and evaluate the triggering risk-factors as well as determinants of overall survival outcome. Such informative data from studies on various settings across the county can help minimizing/preventing AKI incidence and guide to early treatment strategies for better patient outcome.

\section{Material \& Methods}

Type of Study: Hospital based prospective observational study.

Study Setting: Pt JNM Medical College, Raipur \& Dr BR Ambedkar Memorial Hospital, CG, India.

Study Period: Data collection was done over 12 months (August 2017-July 2018).

Study Population: Inclusion Criteria: Age between 1month to 18 years, patients having critical-illness requiring PICU admission, and developing in-hospital AKI (with normal RFT at admission);

Exclusion Criteria: Age $<1$ monts or $>18$ yrs, non-critical patients, pre-existing AKI or CKD, baseline serum creatinine not available at admission (or within 24 hours), refusal for consent.

Criteria set for critical illness of patients in this study: Admission to PICU with any one or more of the following: (i) required mechanical ventilation (ii) required vasopressor support for shock (dopa/dobuta-mine $>10 \mathrm{mcg} / \mathrm{kg} / \mathrm{min} \mathrm{or}$ adrenaline any dose) (iii) impaired level of consciousness (GCS $<7$ ) (iv)acute/fulminant hepatic failure (v) uncontrolled or poorly controlled seizures/ status epilepticus.

Study Methodology \& Data Collection: After obtaining permission \& approval from institutional ethics committee, and written informed-consent was obtained from parents, basic demographic, clinical details and laboratory reports of all enrolled patients were entered from case records into predesigned proforma and then data was compiled in Microsoft Excel-Sheet.

Outcome Variables/Measures: Each subject was followed until final outcome (either survived \& discharged from PICU or death) and last serum creatinine report of each patient was recorded to assess the renal recovery till then, so as to compare renal-function improvement from different AKI stages and with various co-morbidities/risk factors.

Primary Outcome-AKI incidence in critically sick children over study period, AKI-staging, renal-recovery, survival or all cause mortality

Secondary Outcome- Associated risk factors or underlying co-morbidities, determinants of outcome (demographic and disease profile)

Investigations/reports obtained to define outcome measures: (i) Urine output monitoring: input-output chart from PICU patients' records (for clinical AKI detection) (ii)Renal function test: serum creatinine and urea f for baseline Cr and Cr Clearance rate at admission, at the first clinical detection of AKI for pRIFLE staging, and, at discharge or final outcome (death/LAMA) of patient\}(iii) ABG and serum electrolytes ( $\mathrm{K}+/ \mathrm{Na}+/ \mathrm{Ca}++)$ : for dialysis indications (iv) Complete blood count- for anemia/thrombocytopenic and infection evidence (v) Infectious screening- CRP, blood C/S, urine R/M, urine \& other cultures, card test \& PS for Malaria, CXR, USG, CT, other specific tests (vi) For co-morbid factors affecting patient outcome-LFT, RBS, PT/INR, CBC/Platelet, ECG, CXR, lactate by ABG/VBG etc. for MODS /DIC/ARDS/refractory shock /cardiogenic shock/Arrhythmia; $\mathrm{C}_{3} /$ ANA / ds DNA/ASO titres etc. for certain specific etiology of AKI or related problems.

pRIFLE staging/Classification [7]: AKI staging was obtained using pRIFLE-criteria (2007) which is pediatric modification of RIFLE criteria (2004) developed by Acute Dialysis Quality Initiative (ADQI) Group and preferred over alternative AKIN (2004) staging. 
Original Research Article

\begin{tabular}{|c|c|c|}
\hline Stage & Serum Creatinine/clearance criteria & Urine output criteria \\
\hline Risk & eClCr decrease by $25 \%$ & $<0.5 \mathrm{ml} / \mathrm{kg} / \mathrm{h}$ for 8 hours \\
\hline Injury & eClCr decrease by $50 \%$ & $<0.5 \mathrm{ml} / \mathrm{kg} / \mathrm{h}$ for 16 hours \\
\hline Failure & $\mathrm{eClCr}$ decrease by $75 \%$ & $<0.3 \mathrm{ml} / \mathrm{kg} / \mathrm{h}$ for 24 hours \\
& OR eClCr $35 \mathrm{ml} / \mathrm{min}$. & OR anuric for 12 hours \\
& per $1.73 \mathrm{~m} 2$ & \\
\hline
\end{tabular}

In pRIFLE staging being creatinine-based AKI criteria, serum creatinine values are used to calculate an estimated creatinine clearance (eCCl or eClCr) by the Schwartz formula:

$\mathrm{eCCl}(\mathrm{ml} / \mathrm{min} / 1.73 \mathrm{~m} 2)=\mathrm{k}$ x patient's height $(\mathrm{cm}) /$ serum creatinine $(\mathrm{mg} / \mathrm{dl})$,

where, $\mathrm{k}$ is a constant based on patient's gender and age: ' $\mathrm{k}$ values' for preterms or low birth weight less than 1 year (0.33), for full term less than 1 year (0.45); for 2-12 years of age (0.55), and, while it is $(0.55)$ for 13-21 year old females; 13-21 year old males need higher multiplication factor $(0.70)$.

- Baseline and current serum creatinine values are used to calculate a change in eCCl.

- If no baseline serum creatinine is available for 3 months prior to current value, assume normal eCCl $=120$ $\mathrm{ml} / \mathrm{min} / 1.73 \mathrm{~m}^{2}$ for new onset AKI cases.

\section{Statistical Analysis}

- All relevant data were entered into predesigned proforma and analysed (with help of statistician) using Microsoft SPSS software for windows ${ }^{\mathrm{TM}}$ Version 21, IBM ${ }^{\mathrm{TM}}$ Corp NY and Microsoft excel ${ }^{\mathrm{TM}}$ 2007, Microsoft Inc USA.

- Data was expressed as percentage and mean +/_SD

- Student's $t$ test was used to check the significance of difference between two parameters in parametric data.

- Pearson correlation analysis was performed to check the correlation between two categorical variables.

- Fischer's exact test or Chi square test was used to analyse the significance of difference between distributions of the data.

- $\mathrm{P}$ value $<0.05$ was considered as statistically significant.

\section{Results:}

Incidence of new- onset AKI in the study setting: In this hospital based observational study conducted over one-year period, total 1570 patients were admitted in Pediatric intensive care unit (PICU). Those patients who fulfilled the assumed criteria for critical illness (as well as having higher risk of developing AKI) were 1042, but we could finally recruit only 103 of them as study-subjects who actually developed new-onset AKI.

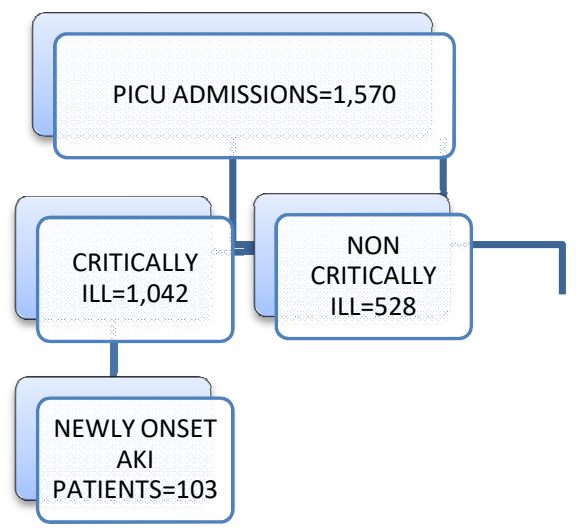

Out total 103 subjects having AKI developed in hospital, 58 subjects were male and 45 subjects were female. We grouped total 1042 PICU patients into 4 major age-groups: 1 month - 1 year (43.9\%), 1 - 6 years (13.7\%), 6-12 years (27\%), and 12-18 years (15.4\%), since clinico-etiological profile or risk-factors of AKI and underlying-disease pattern vary in different age groups. Amongst these critically sick pediatric patients having risk for developing new-onset AKI, females were more than male ( $58 \%$ vs $42 \%)$. 
But, AKI diagnosed in target population was considered to have 'new-onset' only when it developed in- hospital (without pre-existing AKI or CKD), our actual study population-size contracted to include 103 subjects with more male than female ( $\mathrm{n}=58$ vs 45 ) and even there was no significant difference on fractional contribution $-26.2 \%, 21.4 \%, 26.2 \%$ \& $25.2 \%$ by four different age groups respectively (thus reducing age-bias in this study subjects especially with regard to renal and patient survival outcome).

\section{Incidence of new-onset AKI in our study setting}

Incidence Rate $=$ Number of new cases $/$ Sum of person-time at risk

$=103 / 1042 \times 1$ (year)

$=0.098$ or $(9.8 \%)$

Thus, the overall annual incidence of AKI in critically sick PICU-patients was $9.8 \%$ in our study setting.

Table-1: Incidence of new onset AKI over one year study period with age-group \& sex wise distribution

\begin{tabular}{|l|c|c|c|}
\hline \multicolumn{1}{|c|}{ Age Groups } & $\begin{array}{c}\text { Incidence Among } \\
\text { Malesin \% } \\
(\mathbf{N = 4 3 6 )}\end{array}$ & $\begin{array}{c}\text { Incidence Among } \\
\text { Females in \% } \\
(\mathbf{N = 6 0 6})\end{array}$ & $\begin{array}{c}\text { Age-Wise } \\
\text { Incidence rate } \\
\text { (in \% over a year) }\end{array}$ \\
\hline 1 Month -1 Year (N=457) & 9.9 & 2.7 & $\mathbf{5 . 9}$ \\
\hline 1- 6 Years (N=143) & 16.9 & 15.2 & $\mathbf{1 6 . 0}$ \\
\hline 6 - 12 Years (N=282) & 12.7 & 7.5 & $\mathbf{9 . 5}$ \\
\hline 12 - 18 Years (N=160) & 22.6 & 13 & $\mathbf{1 6 . 2}$ \\
\hline Average Incidence & $\mathbf{1 3 . 3}$ & $\mathbf{7 . 4}$ & $\mathbf{9 . 8} \%$ \\
\hline
\end{tabular}

Highest incidence of acute/ new onset kidney injury ( $>16 \%)$ was in adolescent age group 12-18 years and 1-6years preschoolers $(16 \%)$ compared to infants of $<1 \mathrm{yr}$ age-group $(<6 \%)$, despite of the maximum sick patient burden to the PICU was from this youngest age-group. Similarly, opposite to more admissions of females with critical illnesses, males developed more AKI (13.3\% vs 7.4\%).

System- wise underlying disease profile among study subjects: As shown in table 2, maximum new-onset AKI cases were seen with primary disease of central nervous system $(n=27,30 \%)$ followed by cardiovascular system $(n=16,15.5 \%)$ and respiratory system $(\mathrm{n}=15,14.5 \%)$. Other causes were primary infection $(\mathrm{n}=10,9.7 \%)$, blood disorder $(\mathrm{n}=8,7.7 \%)$, hepato-biliary system $(n=7,6.7 \%)$, malignancy $(n=5,4.8 \%)$, renal system $(n=3,2.9 \%)$, endocrine disorder $(n=3,2.9 \%)$, poisoning / snake bite $(\mathrm{n}=4,3.8 \%)$ and others $(\mathrm{n}=5,4.8 \%)$. CNS system $(26.2 \%)$ was most commonly primarily involved in approximately all age groups which further involved to multiple systems and multiple organ damage. Renal diseases itself caused less AKI (2.9\%) as compared to other systemic involvement.

Table-2: Age group wise distribution of different major systems affected with AKI cases

\begin{tabular}{|l|c|c|c|c|c|c|}
\hline $\begin{array}{l}\text { Primary System } \\
\text { Involved }\end{array}$ & $\begin{array}{c}\text { 1 Month - } \\
\text { 1 Year }\end{array}$ & $\begin{array}{c}\text { 1 Year-6 } \\
\text { Years }\end{array}$ & $\begin{array}{c}\text { 6 Years-12 } \\
\text { Years }\end{array}$ & $\begin{array}{c}\text { 12 Years- } \\
\text { 18 Years }\end{array}$ & $\begin{array}{c}\text { Total } \\
\text { Number }\end{array}$ & $\begin{array}{c}\text { Total } \\
\text { Percentage }\end{array}$ \\
\hline Central Nervous System & 7 & 7 & 8 & 5 & 27 & 26.2 \\
\hline Cardio Vascular System & 11 & 2 & 2 & 1 & 16 & 15.5 \\
\hline Respiratory System & 5 & 4 & 3 & 3 & 15 & 14.5 \\
\hline Primary Infection & 3 & 2 & 2 & 3 & 10 & 9.7 \\
\hline Hematological Disorders & 0 & 3 & 4 & 1 & 8 & 7.7 \\
\hline Hepato Biliary System & 1 & 1 & 1 & 4 & 7 & 6.7 \\
\hline Malignancy & 0 & 1 & 3 & 1 & 5 & 4.8 \\
\hline Renal System & 0 & 1 & 1 & 1 & 3 & 2.9 \\
\hline Endocrine Disorder & 0 & 0 & 1 & 2 & 3 & 2.9 \\
\hline Poisoning / Snake Bite & 0 & 0 & 2 & 2 & 4 & 3.8 \\
\hline Others & 1 & 2 & 1 & 1 & 5 & 4.8 \\
\hline Total & $\mathbf{2 8}$ & $\mathbf{2 3}$ & $\mathbf{2 8}$ & $\mathbf{2 4}$ & $\mathbf{1 0 3}$ & $\mathbf{1 0 0}$ \\
\hline
\end{tabular}


Associated risk factors for new-onset AKI among study subjects: Maximum study subjects who developed new onset AKI were associated with risk factors refractory shock $(\mathrm{n}=90,87.4 \%)$ followed by sepsis $(\mathrm{n}=70,68 \%)$ and MODS $(\mathrm{n}=67$, $65 \%$ ). Primarily renal cause itself leads to very less number of AKI cases (approx 9.6\%) as depicted in table 3 .

Table-3: Associated or co morbid risk factors leading to new onset AKI

\begin{tabular}{|c|c|c|c|c|}
\hline Risk Factors & $\begin{array}{c}\text { 1 Month-1 Year } \\
(\mathbf{N}=\mathbf{2 7})\end{array}$ & $\begin{array}{c}\mathbf{1} \text { Year -6 Years } \\
(\mathbf{N = 2 3})\end{array}$ & $\begin{array}{c}\mathbf{6} \text { Years-12 } \\
\text { Years }(\mathbf{N}=\mathbf{2 7})\end{array}$ & $\begin{array}{c}\mathbf{1 2} \text { Years- 18 } \\
\text { Years }(\mathbf{N}=\mathbf{2 6})\end{array}$ \\
\hline Refractory Shock & $22(81.5 \%)$ & $20(87 \%)$ & $25(92.6 \%)$ & $22(84.6 \%)$ \\
\hline Sepsis / Pneumonia & $23(85.1 \%)$ & $16(69.5 \%)$ & $17(62.9 \%)$ & $14(53.8 \%)$ \\
\hline MODS & $15(5.5 \%)$ & $15(65.2 \%)$ & $19(70.3 \%)$ & $18(69.2 \%)$ \\
\hline Severe Anaemia & $3(1.1 \%)$ & $10(43.4 \%)$ & $10(37 \%)$ & $3(11.5 \%)$ \\
\hline CCF & $8(29.6 \%)$ & $3(13 \%)$ & $8(29.6 \%)$ & $5(19.2 \%)$ \\
\hline Status Epilepticus & $5(18.5 \%)$ & $6(26 \%)$ & $3(11.1 \%)$ & $5(19.2 \%)$ \\
\hline AGE / DVD (Dehydration) & $4(14.8 \%)$ & $4(17.3 \%)$ & $2(7.4 \%)$ & $1(3.9 \%)$ \\
\hline HIE Sequelae & $1(3.7 \%)$ & $4(17.3 \%)$ & $3(11.1 \%)$ & $0(0 \% 0$ \\
\hline Nephrotic Syndrome / PEM & $0(0 \%)$ & $2(8.6 \%)$ & $1(3.7 \%)$ & $2(7.6 \%)$ \\
\hline Renal / Other Malignancy & $0(0 \%)$ & $2(8.7 \%)$ & $2(7.4 \%)$ & $1(3.9 \%)$ \\
\hline AGN/PIGN/HUS/SLE & $0(0 \%)$ & $0(0 \%)$ & $1(3.7 \%)$ & $0(0 \%)$ \\
\hline Tumor Lysis Syndrome & $0(0 \%)$ & $0(0 \%)$ & $1(3.7 \%)$ & $0(0 \%)$ \\
\hline
\end{tabular}

Other associated risk factors were severe anaemia (25.2\%), CCF (23.2\%), status epilepticus (18.4 \%), AGE related dehydration (10.6\%), HIE sequelae $(7.7 \%)$, nephrotic syndrome $(4.8 \%)$.

Bacteriological Culture Profile amongst Septic Subjects: Most common organisms grown on culture-proven sepsis (60\% of critical patients with AKI in our PICU) were- klebsiella (38\%), CONS (28\%), pseudomonas (15\%), enterococcus (6.5\%), Acinetobacter (5\%), Citrobacter (3.3\%); while staphaureus $(3.3 \%)$ and streptococcus pyogenes $(1.7 \%)$. Overall Gram +ve organisms contributed less (about 40\%) compared to usually nosocomial/ hospital-acquired Gram-ve organisms $60 \%$ ). Around $2 / 3^{\text {rd }}$ cases of klebsiella positive sepsis was found in young infants aged $<2$ yrs.

\section{Major Outcome Variables (with respect to chance of renal-recovery and patient-survival):}

AKI Staging In Our Study Subjects: In all age groups, injury and failure was the most common pRIFLE stages at which patients were first time recognized as AKI. As most of worsening patients died at 'failure' stage, thus 'loss and ESRD' stages could not be observed except in single patient who survived with prolonged AKI $>4$ wks and ultimately died of MODS.

Table-4: AKI stages on first recognition in different age groups.

\begin{tabular}{|c|c|c|c|}
\hline Age Groups & Risk & Injury & Failure \\
\hline 1 Month-1 Year & $2(1.9 \%)$ & $13(12.6 \%)$ & $9(8.7 \%)$ \\
\hline 1 Year-6 Years & $4(3.8 \%)$ & $9(8.7 \%)$ & $11(10.6 \%)$ \\
\hline 6 Years-12 Years & $3(2.9 \%)$ & $13(12.6 \%)$ & $11(10.6 \%)$ \\
\hline 12 Years-18 Years & $3(2.9 \%)$ & $11(10.6 \%)$ & $13(12.6 \%)$ \\
\hline Total & $12(11.8 \%)$ & $46(10.8 \%)$ & $44(43.1 \%)$ \\
\hline
\end{tabular}

According to pRIFLE staging, maximum AKI cases were firstly detected in this study, when they had reached to 'injury' stage (44.6\%) and 'failure' stage (42.7\%). Early detected at 'risk' stage the numbers were small (only $11.6 \%)$.

Rapidity or duration to develop in-hospital AKI: Maximum AKI developed within 3 days (61.1\%) of hospital stay followed by 4-7 days (29.1\%). AKI developed earlier in younger age groups. 
Dialysis Requirement: 29 out of total 103 study subjects (28\%) were indicated for dialysis/hemodialysis. But dialysis could not be done in most of subjects due to low GCS, hemodynamic instability and poor resources in the study-setting.

Overall patient survival outcome: 90 patients $(87.4 \%)$ died due to complications of worsening AKI or coexisting MODS/refractory shock. Another three more patients (2.9\%) partially improved to better AKI stage and but died due to other co morbid condition.

\section{Determinant factors affecting patient outcome:}

i. AKI stage at first recognition (see table 5)

Table-5: Association between AKI -stages and patient outcome

\begin{tabular}{|c|c|c|c|}
\hline \multirow{2}{*}{$\begin{array}{c}\text { AKI stage (at first } \\
\text { detection) }\end{array}$} & Final patient-outcome & Total \\
\cline { 2 - 4 } & Discharge & Death & $\mathbf{1 2}$ \\
\hline \multirow{2}{*}{ Risk } & 3 & $9.5 \%$ & $11.7 \%$ \\
\cline { 2 - 4 } & $37.5 \%$ & $\mathbf{4 5}$ & $\mathbf{4 6}$ \\
\hline \multirow{2}{*}{ Injury } & 1 & $47.3 \%$ & $44.7 \%$ \\
\hline \multirow{2}{*}{ Failure } & $12.5 \%$ & $\mathbf{4 0}$ & $\mathbf{4 4}$ \\
\hline \multirow{2}{*}{ LOSS } & 4 & $42.1 \%$ & $42.7 \%$ \\
\hline
\end{tabular}

Association between AKI staging and recovery was performed using Chi square test. No significant association was detected between these two parameters.

ii. Other multiple factors determining the final patient outcome: various factors could have affected the disease course and were related to high all- cause mortality (see table 6) -

Table-6: Determinant factors for fatal outcome in different age groups

\begin{tabular}{|c|c|c|c|c|}
\hline $\begin{array}{c}\text { Determinant Factors } \\
\text { (other than AKI stage) }\end{array}$ & $\begin{array}{c}\mathbf{1} \text { Month-1 Year } \\
(\mathbf{N}=\mathbf{2 5})\end{array}$ & $\begin{array}{c}\mathbf{1}-\mathbf{6} \text { Years } \\
\mathbf{( N = 2 1 )}\end{array}$ & $\begin{array}{c}\mathbf{6}-\mathbf{1 2} \text { Years } \\
\mathbf{( N = 2 4 )}\end{array}$ & $\begin{array}{c}\mathbf{1 2} \mathbf{- 1 8} \\
\text { Years } \\
(\mathbf{N}=\mathbf{2 5})\end{array}$ \\
\hline Refractory Shock & $24(96 \%)$ & $20(95.2 \%)$ & $22(91.6 \%)$ & $24(96 \%)$ \\
\hline Sepsis & $24(96 \%)$ & $16(76.2 \%)$ & $12(50 \%)$ & $17(68 \%)$ \\
\hline MODS & $18(72 \%)$ & $14(66.6 \%)$ & $17(70.8 \%)$ & $18(72 \%)$ \\
\hline Severe Anaemia & $3(12 \%)$ & $8(38 \%)$ & $9(37.5 \%)$ & $5(20 \%)$ \\
\hline ARDS & $1(4 \%)$ & $2(9.5 \%)$ & $2(8.3 \%)$ & $3(12 \%)$ \\
\hline AGE With Severe Dehydration & $2(8 \%)$ & $3(14.3 \%)$ & $2(8.3 \%)$ & $0(0 \%)$ \\
\hline Malignancy (ATLS ) & $0(0 \%)$ & $1(4.8 \%)$ & $2(8.3)$ & $2(8 \%)$ \\
\hline AGN Or Nephritic Related & $0(0 \%)$ & $0(0 \%)$ & $1(4.2 \%)$ & $2(8 \%)$ \\
\hline Hypertensive Emergency & $0(0 \%)$ & $2(9.5 \%)$ & $0(0 \%)$ & $0(0 \%)$ \\
\hline Severe Hypoproteinemia & & & & 0 \\
\hline
\end{tabular}

Refractory shock $(n=90,94.7 \%)$ followed by sepsis $(n=69,72.6 \%)$ and MODS $(n=67,70.5 \%)$ were major factors to determine fatal outcome in newly onset AKI cases. Other determinant factors for fatal outcome were severe anaemia $(n=25,26.3 \%)$, ARDS $(n=8,8.4 \%)$, AGE with severe dehydration $(n=7,7.4 \%)$, malignancy $($ ATLS $)(n=5, n=5.2)$ and severe hypoproteinemia $(n=2,2 \cdot 1 \%)$. 
Renal Recovery (AKI Reversal) and its determinants in this study: Only 6 (5.8\%) patients out of total 103 patients with new onset AKI completely improved with their serum creatinine improved to near baseline and were successfully discharged; while 7 (6.8\%) patients were shifted to the ward from PICU with partial renal recovery. Majority of subjects $(\mathrm{n}=90,87.4 \%)$ showed worsening renal function results over their hospital stay period.

Table-7: Association between determinant factors and AKI recovery status.

\begin{tabular}{|c|c|c|c|c|}
\hline \multirow[t]{2}{*}{ Determinant factors } & \multicolumn{2}{|c|}{ AKI Recovery (renal status) } & \multirow{2}{*}{ Total } & \multirow[b]{2}{*}{ P Value } \\
\hline & Improved & Worsened & & \\
\hline \multirow{2}{*}{ Sepsis } & 9 & 66 & 75 & 0.493 \\
\hline & $69.2 \%$ & $73.3 \%$ & $72.8 \%$ & \\
\hline \multirow{2}{*}{ MODS } & 4 & 64 & 68 & \multirow{2}{*}{0.006} \\
\hline & $30.8 \%$ & $71.1 \%$ & $66.0 \%$ & \\
\hline \multirow{2}{*}{ Refractory shock } & 3 & 88 & 91 & \multirow{2}{*}{$<0.0001$} \\
\hline & $23.1 \%$ & $97.8 \%$ & $88.3 \%$ & \\
\hline \multirow{2}{*}{ ARDS } & 1 & 8 & 9 & \multirow{2}{*}{0.683} \\
\hline & $7.7 \%$ & $8.9 \%$ & $8.7 \%$ & \\
\hline \multirow{2}{*}{ Severe anemia } & 3 & 24 & 27 & \multirow{2}{*}{0.541} \\
\hline & $23.1 \%$ & $26.7 \%$ & $26.2 \%$ & \\
\hline \multirow{2}{*}{ Severe hypo-proteinemia } & 0 & 2 & 2 & 0.762 \\
\hline & $.0 \%$ & $2.2 \%$ & $1.9 \%$ & \\
\hline \multirow{2}{*}{ AGE with severe dehydration } & 3 & 5 & 8 & \multirow{2}{*}{0.061} \\
\hline & $23.1 \%$ & $5.6 \%$ & $7.8 \%$ & \\
\hline \multirow{2}{*}{ Nephrotoxic changes } & 0 & 0 & 0 & \\
\hline & $0 \%$ & $0 \%$ & & \\
\hline \multirow{2}{*}{ Malignancy } & 0 & 5 & 5 & \multirow{2}{*}{.502} \\
\hline & $.0 \%$ & $5.6 \%$ & $4.9 \%$ & \\
\hline \multirow{2}{*}{ AGN/Nephritic } & 0 & 2 & 2 & \multirow{2}{*}{0.762} \\
\hline & $.0 \%$ & $2.2 \%$ & $1.9 \%$ & \\
\hline \multirow{2}{*}{ Total } & 13 & 90 & 103 & \\
\hline & $100.0 \%$ & $100.0 \%$ & $100.0 \%$ & \\
\hline
\end{tabular}

Association between determinant factors and AKI recovery was performed using Fischer's exact test. MODS ( $p=0.006$ ) and refractory shock $(\mathrm{p}=0.0001)$ were the only factors showing significant association with worsened AKI recovery.

\section{Discussion}

The overall annual incidence of new-onset AKI amongst 1042 critically-ill children admitted to PICU of Pt JNM Medical college, Raipur, CG during the study period was $9.8 \%(n=103)$. A similar observational study by Mehta $\mathrm{P}$ et al [1] reported overall incidence of newonset AKI in critically sick PICU subjects to be $36.1 \%$, while it was only $9 \%$ in non-critically ill pediatric subjects. As observed by another study of Krishnamurthy $\mathrm{S}$, et al[2], the incidence of AKI was $5.2 \%$ amongst all pediatric patients admitted to wards (including PICU), while it was as high as $25.1 \%$ among isolated PICU admissions.
Most number of cases of AKI developed in young infants in our study, but adolescents also contributed comparable number of cases amongst our subjects (around 25\% from each age-group) and rather high agewise incidence among adolescents $(16.2 \%$ versus $5.9 \%$ ). Weljad Al Jbur, et al observed most significant risk factors of AKI in critically ill children were the younger age group 1 month to 1 year $(42.2 \%)$ [3]. The clinico-etiological profile of study subjects by affected primary system, majority of cases were having CNS diseases (30.6\%) followed by CVS (16\%) and respiratory diseases $(16.4 \%)$, while isolated renal system 
disease was least common (3\%). Although system-wise, we obtained systemic infections (multisystem-sepsis) at fourth position, but actually overall infection with/ without culture proven septicemia contributed to most common cause of critical illness and AKI in PICU.

By primary disease-diagnosis at admission, most common diagnoses were sepsis/ pneumonia (with or without failure to thrive), dyselectrolytemia (with/ without underlying acute gastroenteritis), pyogenic meningitis, CHDs (with/without CCF), severe malaria, sickle cell crises, AES (acute viral encephalitis/ syndrome); while primary renal cases were few (3\%).

In young infants ( $<1$ year age), CVS (10.6\%) was primarily involved system (with majority having CHDs), followed by CNS $(6.7 \%)$, respiratory diseases $(5 \%)$ excluding systemic sepsis $(3 \%)$. Severe malaria constituted about $10 \%$ of all AKI cases in this observational study. Older children and adolescents presented with acquired infectious as well as noninfectious diseases like hematological- disorders (sickling/ thalessemia-8.7\%, malignancy-4.8\%), poisoning / snakebite (total 4\%) and DKA (3\%) causing multi-system damages.

Maximum patients developing any stage of AKI were associated with three commonest risk-factors e.g. refractory shock $(87.4 \%$ cases $)$ followed by sepsis (68\%) and MODS (65\% cases). Poonam Mehta, et al [1], conducted a similar study and considered most common etiology of AKI to be acute tubular necrosis (ATN) which was associated with sepsis and shock as the chief predisposing conditions. Similarly, sepsis (45.35\%) and MODS (40.6\%) were the most significant risk factors of AKI in critically ill children in a study by Weljad Al Jbur, et al [3].

Sepsis in our study was in the form of pneumonia, septicemia, meningitis/meningo-encephalitis and few had clinical sepsis without obvious focus. Most common organisms grown amongst $60 \%$ culture-proven septic and critical patients with AKI in the study setting were- klebsiella (38\%), CONS (28\%), pseudomonas $(15 \%)$, enterococcus (6.5\%), acinetobacter (5\%), citrobacter (3.3\%); while staph. Aureus (3.3\%) and streptococcus pyogenes $(1.7 \%)$. Thus overall Gram +ve organisms contributed less (40\% cases) compared to usually occurring nosocomial /hospital-acquired Gram ve organisms $(60 \%)$. Around $2 / 3^{\text {rd }}$ cases of Klebsiella positive sepsis was found in young infants aged $<2$ yrs. A similar study done by Singh Naz, et al (1994)[8] also supported that the most common organisms isolated from critically ill children were Gram negative bacteria
(53\%), Gram positive bacteria (27\%), and fungi (9\%). Another study by Akash Deep, et al (2002)[9] in a south Indian PICU showed that Klebsiella (33.3\%) was the most common pathogen followed by E. coli (16.7\%) to cause nosocomial PICU infection.

Maximum new-onset AKI developed within 3 days of hospital or PICU stay, as seen in $62 \%$ of our enrolled subjects. The staging of new-onset AKI by pRIFLE criteria [7] revealed that most common stage during case-detection were having 'injury'/stage-I (44.6\%) and 'failure'/stage-F (42.7\%) and least patient survived till or could be observed till developing stage 4 criteria of 'renal loss'.

In our study, 28\% of all AKI cases had indications for hemodialysis or RRT, although none could receive dialysis therapy due to certain technical and resource constraints (especially lack of pediatric dialysis unit and inadequate provisions even for timely needed acute peritoneal dialysis). Similar to our study setting with RRT facility-limitations, a study by Touza Po P, et alalso concluded that RRT was required in large proportion $(60.1 \%)$ of cases, although that could not be performed due to very low GCS and hemodynamic status of patients and poor resource [10]. In another study by Bagshaw S M, et al reasons given by them for not starting RRT (not mutually exclusive) were limitations of support, adequate urine output, and plan to observe. Mortality was higher in those not receiving RRT due to limitations [11].

In our study, overall patient-outcome analysis revealed high mortality after new-onset AKI in patients already critically sick at admission and it figured upto $92 \%$.

Although most of deaths ( $87 \%$ mortality) were related to or associated with worsening renal function or nonrecovery $\mathrm{AKI}$, around $5 \%$ patient had shown partial improvement to better AKI stage but died due to other co-morbid conditions related to their critical illness.

Among determinants of overall poor AKI-reversal and patient-survival outcome in our setting, major factors were sepsis $(72.6 \%)$, refractory shock $(94.7 \%)$, MODS (70.5\%), and unavailability of adequate and timely renal replacement therapy. In a similar study by Yegenage $\mathrm{T}$, et al (2010) [12], Sepsis was thecommon cause of acute renal failure in intensive care units (ICU) with mortality rates as high as $60 \%$. Both fatal outcome and worsening AKI stage (or non-recovery from ARF) showed significant association with each of major outcome determinants - MODS $(\mathrm{p}<0.05)$ and refractory shock $(\mathrm{p}<0.05)$ respectively. 
Although there were maximum deaths with RIFLE stage 2 (Injury-47\%) and stage3 (Failure-42\%) accounting for $>89 \%$ together, no statistically significant association was detected between different AKI staging (by pRIFLE criteria) and AKI recovery/ reversal (Pearson Chi-square, $p$ value $=0.117$ ) same as between AKI stages and patient-survival outcome ( $p$ value $=0.067)$.

Further progression of AKI stages to 'Loss'-stage 4 or prolonged AKI ( $>4$ weeks) was documented in numerically single $(1 \%)$ patient of 103 critically ill study subjects, as most patients died in AKI stage 2 or 3. This would have nullified $p$-value significance of possible poor outcome trends with progressive AKI stages.

\section{Conclusion}

Significant proportion (approximately 10\%) of critically ill patients admitted to PICU developed new-onset AKI. Pre-school and adolescent age-group are equally vulnerable to develop AKI during critical illness having any primary disease diagnosis at admission. Major comorbid risk factors for developing AKI and determinants of AKI-worsening (or poor recovery) as well as poor patient-survival outcome in this study were sepsis, refractory shock and MODS. Most patient with AKI stage 2 (injury) and stage 3 (failure) or stage 4 (loss) had high mortality.

What this study adds to existing knowledge: Timely detection of AKI in early stages using pRIFLE or RIFLE criteria amongst all critically ill pediatric patients may help to reduce disease worsening and fatal outcome with timely reno-protective interventions including dialysis/RRT (if needed) along with appropriate management of underlying and co-morbid fatal condition.

Contributions: BNR, SKR and SP conceptualized, designed and analyzed the study. SKR was directly involved in paper writing drafting and will be primary correspondent author. YKV conducted data-collection and helped in analysis and manuscript writing. DA helped in statistical analysis.

Funding: Nil, Conflict of interest: None initiated, Permission from IRB: Yes

\section{References}

1. Mehta P, Sinha A, Sami A, et al. Incidence of acute kidney injury in hospitalized children. Indian Pediatr. 2012 Jul;49(7):537-42. Epub 2011 Dec 17.
2. Krishnamurthy S, Mondal N, Narayanan P, et al. Incidence and etiology of acute kidney injury in southern India. Indian J Pediatr. 2013 Mar; 80 (3): 1839. doi: 10. 1007/s 12098-012-0791-z. Epub 2012 Jun 14.

3. Al-Jboor W, Almardini R, Al Bderat J, et al. Acute kidney injury in critically ill child. Saudi J Kidney Dis Transpl. 2016 Jul-Aug;27(4):740-7. doi: 10.4103/13192442.185236.

4. Palmieri T, Lavrentieva A, Greenhalgh D. An assessment of acute kidney injury with modified RIFLE criteria in pediatric patients with severe burns. Intensive Care Med. 2009 Dec; 35(12):2125-9. doi: 10.1007/ s00134-009-1638-6. Epub 2009 Sep 15.

5. Kendirli T, Ekim M, Ozçakar ZB, et al. Renal replacement therapies in pediatric intensive care patients: experiences of one center in Turkey. Pediatr Int. 2007 Jun; 49(3):345-8. DOI:10.1111/j.1442-200X. 2007. 02376.x.

6. Bellomo R, Ronco C, Kellum JA, et al. Acute renal failure - definition, outcome measures, animal models, fluid therapy and information technology needs: the Second International Consensus Conference of the Acute Dialysis Quality Initiative (ADQI) Group. Crit Care. 2004 Aug; 8 (4):R204-12. Epub 2004 May 24. DOI:10.1186/cc2872.

7. Akcan-Arikan A, Zappitelli M, Loftis LL, et al. Modified RIFLE criteria in critically ill children with acute kidney injury. Kidney Int. 2007 May;71(10): 1028-35. Epub 2007 Mar 28. DOI:10.1038/ sj.ki. 5002231 .

8. Singh-Naz, Nalini; Sprague, Bruce M.; Patel, Kantilal M.; Pollack, Murray M. Risk Factors For Nosocomial Infection In Critically Ill Children:A Prospective Cohort Study. Crit Care Med. 1996May; 24 (5): $875-8$.

9. Deep A, Ghildiyal R, Kandian S, et al. Clinical and microbiological profile of nosocomial infections in the pediatric intensive care unit (PICU). Indian Pediatr. 2004 Dec; 41(12):1238-46.

10. Touza Pol P, Rey Galán C, Medina Villanueva JA, et al. [Severe acute kidney injury in critically ill children: Epidemiology and prognostic factors]. An Pediatr (Barc). 2015 Dec; 83 (6): 367-75. doi: 10. 1016/j. anpedi. 2015. 01. 009. Epub 2015 Mar 6. 
11. Bagshaw SM, Lapinsky S, Dial S, et al. Acute kidney injury in septic shock: clinical outcomes and impact of duration of hypotension prior to initiation of antimicrobial therapy. Intensive Care Med. 2009 May; 35(5): 871-81. doi: 10.1007/s00134-008-1367-2. Epub 2008 Dec 9.
12. Yegenaga I, Tuglular S, Ari E, et al. Evaluation of sepsis/systemic inflammatory response syndrome, acute kidney injury, and RIFLE criteria in two tertiary hospital intensive care units in Turkey. Nephron Clin Pract. 2010;115(4): c276-82. doi: 10.1159/000313486. Epub 2010 Apr 28.

\section{How to cite this article?}

Rao B.N, Rathia S.K, Phuljhele S, Verma Y.K, Amle D. Incidence, risk factors, clinical profile, and determinants (affecting outcome) of new onset acute kidney injury developing in critically Ill patients in pediatric intensive care unit of a tertiary hospital in middle India. Int J Pediatr Res. 2019;6(05):252-261.doi:10.17511/ijpr. 2019.i05.10 